九州大学学術情報リポジトリ

Kyushu University Institutional Repository

\title{
The Effect of Chemical Surface Treatment on Mechanical Performance of Electrically Conductive Adhesives
}

S. H. Sheikh Md. Fadzullah

Mechanical Engineering Department, Universitas Sebelas Maret

M. M. Nasaruddin

Fakulti Kejuruteraan Mekanikal, Universiti Teknikal Malaysia Melaka

Z. Mustafa

Fakulti Kejuruteraan Pembuatan, Universiti Teknikal Malaysia Melaka

W. A. W. A. Rahman

Fakulti Kejuruteraan Mekanikal, Universiti Teknikal Malaysia Melaka

他

https://doi.org/10.5109/4068625

出版情報 : Evergreen. 7 (3)，pp.444-451，2020-09. 九州大学グリーンテクノロジー研究教育センター バージョン：

権利関係 : 


\title{
The Effect of Chemical Surface Treatment on Mechanical Performance of Electrically Conductive Adhesives
}

\author{
S.H. Sheikh Md. Fadzullah ${ }^{1,2 *}$, M.M. Nasaruddin ${ }^{1}$, Z. Mustafa ${ }^{3}$, \\ W.A.W.A. Rahman ${ }^{1}$, G. Omar ${ }^{1,2}$, M.A. Salim ${ }^{1,2}$ and M.R. Mansor ${ }^{1,2}$ \\ ${ }^{1}$ Fakulti Kejuruteraan Mekanikal, Universiti Teknikal Malaysia Melaka, \\ Hang Tuah Jaya, 76100 Durian Tunggal, Melaka, Malaysia. \\ ${ }^{2}$ Centre for Advanced Research on Energy, Universiti Teknikal Malaysia Melaka, \\ Hang Tuah Jaya, 76100 Durian Tunggal, Melaka, Malaysia. \\ ${ }^{3}$ Fakulti Kejuruteraan Pembuatan, \\ Universiti Teknikal Malaysia Melaka, Hang Tuah Jaya, \\ 76100 Durian Tunggal, Melaka, Malaysia. \\ E-mail: *hajar@utem.edu.my
}

(Received January 23, 2020; Revised April 8, 2020; accepted September 3, 2020).

\begin{abstract}
Adhesion strength of electrically conductive adhesive (ECA) could be enhanced through surface treatment. This paper characterizes the multiwalled carbon nanotube (MWCNT) filled ECA with varying MWCNT filler loading. Here, the focus is on the effect of chemical treatment on aluminium substrate surface treatment onto the adhesion strength of the ECA as per ASTMD 1002. The chemically etched aluminum substrate provides the largest effective bond area between ECA/substrate interface, with the highest shear strength of the ECA. More specifically, the ECA with 6 wt.\% MWCNT filler loading exhibit an optimum lap shear strength, showing an adhesive-cohesive failure mode.
\end{abstract}

Keywords: ECA; MWCNT; shear roughness; lap shear strength; surface wettability

\section{Introduction}

Nowadays, with increasing awareness to protect the environment ${ }^{1}$, the use of lead-based solder for electronic components interconnection in the printed circuit board (PCB) is gradually replaced by the lead-free electrically conductive adhesive (ECA) in microelectronic industry. ECA is a type of composite material ${ }^{2}$, which is made up of a matrix or more commonly known as a binder and a conductive filler, typically either from a metal-based material. The contact between substrate and ECA allows current flow through them, which conductive fillers, allowing electron movement by their contact between their suspended particles in the adhesives ${ }^{3,4)}$. There are few advantages of using ECA as compared to lead-based solder for electronic component interconnection, the adhesives are lead-free, less and simple processing steps which reduce the production cost, and finer pitch due to small particles of filler ${ }^{5,6)}$.

In the last couple of years, carbon nanotube (CNT), with its many advantageous features and characteristics ${ }^{7}$, has been introduced to replace the use of metallic material as a conductive filler. The use of CNT can increase the performance and properties of ECA. The improvement of
ECA when using CNT as a filler instead of metallic material is in terms of improved strength and modulus, high thermal conductivity and good thermal stability, and high capacity of current flow ${ }^{8)}$.

The critical aspect of the fine-pitch interconnection field is the adhesion strength of the ECA. It is because ECA is detrimental to shock encountered during handling, assembly, and lifetime which require excellent adhesion bond between ECA/substrate interface. The overall adhesion strength of ECA is from two types of adhesion mechanisms: these being chemical and physical bonding. The latter adhesion mechanism is expected to have good adhesion strength of polymer in the ECA towards the substrate with a rougher surface in which the rougher surface provides more contact surface area between polymer/substrate interface to establish excellent interfacial mechanical interlocking ${ }^{5}$.

In this study, the ECA is formulated using multi-walled carbon nanotube (MWCNT) conductive filler in an epoxybased ECA composites. The main objective of this study is to investigate the effect of chemical treatment on the aluminum substrate surface towards the mechanical performance of the ECA, with varying MWCNT filler loading, in terms of the lap shear strength. Aluminium 
alloy is the substrate material of choice since this material is well-known for its useful applications in widespread industries from electronics to aerospace, automotive, general engineering ${ }^{9-11)}$.

\section{Materials and Methodology}

\subsection{Materials Selection}

Aluminum alloy was used as the substrate. There are two types of chemicals used for chemical surface treatment on an aluminum substrate, which is hydrochloric acid $(\mathrm{HCl})$ and sodium hydroxide $(\mathrm{NaOH})$. $\mathrm{HCl}$ solution used was a QReC Hydrochloric Acid Solution $1 \mathrm{~mol} / 1(1 \mathrm{~N})$ with a molecular weight of 36.46 $\mathrm{g} / \mathrm{mol}$. The ECA composite is consists of a polymer matrix and conductive filler. The polymer matrix used was Araldite 506 Epoxy Resin Brand Sigma-Aldrich with a relative density of $1.168 \mathrm{~g} / \mathrm{cm} 3$. The conductive filler used was multi-walled carbon nanotube (MWCNT) from Amorphous Materials with an outside diameter of 10-20 $\mathrm{mm}$, length of $10-30 \mathrm{~nm}$, purity of $>95 \%$, and true density of $2.1 \mathrm{~g} / \mathrm{cm} 3$. The epoxy curing agent used was JEFFAMINE D-230 Polyether amine with a viscosity of $9.5 \mathrm{cSt}$ and a density of $0.948 \mathrm{~g} / \mathrm{ml}$ at $25{ }^{\circ} \mathrm{C}$.

\subsection{Chemical Surface Treatment}

The aluminum alloy substrate was cut to dimensions of $25.4 \mathrm{~mm} \times 101.6 \mathrm{~mm} \times 1.6 \mathrm{~mm}$ in accordance to the ASTM D1002. The surface of the substrates was wiped with acetone to remove dirt, grease, and other contamination. Then, the substrate was immersed in a 5\% $\mathrm{NaOH}$ solution at $40{ }^{\circ} \mathrm{C}$ for $120 \mathrm{~s}$ for the alkaline etching process. The process followed by acidic etching on the substrates which the substrates were immersed in 3.6\% $\mathrm{HCl}$ solution at $40{ }^{\circ} \mathrm{C}$ for $300 \mathrm{~s}$. At the last stage, the substrates were alkaline etched again with the same $\mathrm{NaOH}$ solution condition for $300 \mathrm{~s}$. The substrates were rinsed with distilled water after underwent each etching process to prevent the mixture of different chemical solutions.

\subsection{Surface Morphology}

Microstructural characterization on surfaces of asreceived and chemical etched aluminum substrates was conducted by using a ZEISS Axioskop 2 MAT low power microscope and a Shodensha Model GR3400 3D optical profilometer. The former microscope used to generate a 2D microscopic image while the latter microscope used to generate a 3-D microscopic image. Scanning electron microscopy (SEM) was used to the characterized microstructure of failed ECA via lap shear tensile test which the ECA was sputter-coated with a conductive material as SEM technique required good material conductivity of specimen to generate a more representative image.

\subsection{Surface Roughness}

The surface roughness of aluminum substrates was measured using a Mitutoyo stylus profilometer model SJ410 in which the roughness measurement is based on the change of vertical position of the moving probe along the surface line of interest. The profilometer generates 2-D profiles and average surface roughness, $\mathrm{Ra}$, of the aluminum substrate. $\mathrm{Ra}$ is the average deviation of height's absolute value from the mean line, recorded along the line of interest ${ }^{12)}$, which is expressed in Eq. (1):

$$
R_{a}=\frac{1}{L} \int_{0}^{L} Z(x) d x
$$

$\mathrm{Ra}=$ Average surface roughness, $\mu \mathrm{m}$

$\mathrm{L}=$ Distance of line of interest, $\mu \mathrm{m}$

$\mathrm{Z}=$ Vertical distance between the data point and mean line, $\mu \mathrm{m}$

The overlap area of the aluminium substrate was divided into three parts, and each part underwent the surface roughness measurement. The data of surface roughness, Ra for each substrate were averaged.

\subsection{Contact Angle}

The contact angle test was performed to characterize the surface wettability of aluminum substrates. The test was following ASTM D5725 as a standard guideline. Microliter pipette brand Eppendorf Research plus was set to release $0.5 \mu \mathrm{l}$ of the drop. The liquid used to drop onto the substrate surface was distilled water. The overlap area was divided into three parts and the liquid was dropped on each part. The contact angle for the left and right sides of the drop was measured. Then, the readings of the contact angle of all drops in each sample were averaged.

\subsection{ECA Preparation}

The ECAs were prepared in a dry and clean plastic container. The epoxy and hardener with a ratio of 100:30 were mixed and stirred manually for 1 minute. Then, MWCNT with varied loading of 5 wt.\%, 6 wt.\%, and 7 wt.\% were mixed well with the mixture for 5 minutes to form the uncured ECA. The uncured ECA was applied on substrates and then cured in an oven at $100{ }^{\circ} \mathrm{C}$ for 30 minutes.

\subsection{Electrical Characterizations}

The electrical sheet resistance test of printed ECA on the polycarbonate substrate was conducted as per ASTM F390 as a standard guideline. The test was conducted by measuring the sheet resistance of 6-printed ECAs on the substrate with using of JANDEL In-Line For-Point Probe. Initially, the 3M Scotch tape was applied on the substrate to form a printed area with a depth of two-layer of the tape thickness. The small amount of ECA was placed on the printed area and was squeezed by a small metal sheet to form uniform thin application of printed ECA, as depicted in Fig 1. Then, the printed ECAs were cured in an oven. 


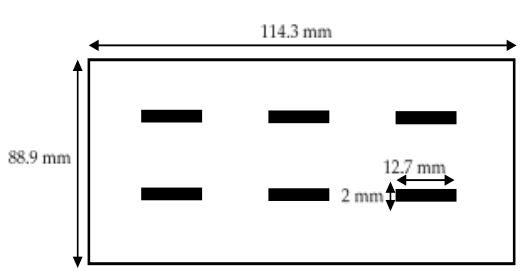

Fig. 1: Schematic view of 6-printed ECAs on a polycarbonate substrate

\subsection{Lap Shear Tensile Test}

The lap shear tensile test was conducted with referring to ASTM D1002 as a standard guideline. The aluminum substrates were prepared with a dimension of $101.6 \mathrm{~mm} \times$ $25.4 \mathrm{~mm} \times 1.6 \mathrm{~mm}$, and the overlap area was $25.4 \mathrm{~mm} \times$ $12.7 \mathrm{~mm}$, as illustrated in Fig. 2.

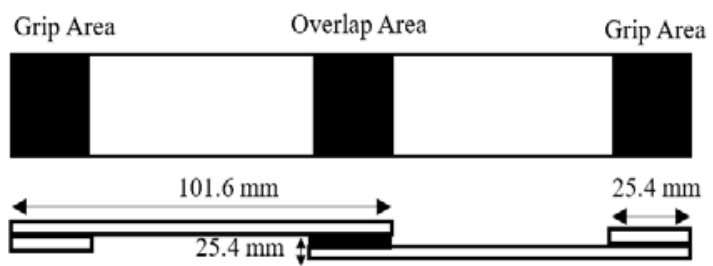

Fig. 2: Schematic view of lap shear tensile test specimen with dimension in $\mathrm{mm}$

The ECA was placed on the entire overlap area. Then, the aligned substrates were clamped with clips to get uniform $0.1 \mathrm{~mm}$ thickness of the ECA joint. A small aluminum plate with thickness $1.6 \mathrm{~mm}$ was placed at the grip area of the substrate to ensure the centric force applied on the ECA joint during the test. Universal Material Testing (AG-10kNX) was used with a jig speed of $1.3 \mathrm{~mm} / \mathrm{min}$. The lap shear strength expressed in Eq. (2):

$$
\tau_{\text {Lap }}=\frac{F_{\text {Max }}}{A}
$$

whereby $\tau_{\text {Lap }}=$ Lap shear strength LSS (MPa),

$F_{\text {Max }}=$ maximum tensile force $(\mathrm{N})$ and $\mathrm{A}=$ adhesive overlap area $\left(\mathrm{m}^{2}\right)$.

\section{Results and discussion}

The experimental results attained from this research work are presented in the following sections.

\subsection{Sheet Resistance}

The sheet resistance was measured on the ECA with 5 wt.\%, 6 wt.\%, and 7 wt.\%. MWCNT filler loading. Based on the experimental results in Fig. 3, sheet resistance decreases when filler loading is increased from $5 \mathrm{wt} . \%$ to 7 wt.\%. As expected, an increase of MWCNT loading contributes to lower electrical resistivity in ECA due to an increase of contact, an increase of probability of continuous linkage, and an enhancement formation of a three-dimensional network between MWCNT conductive particles in $\mathrm{ECA}^{5,13)}$. The result is in good agreement with demonstrated by Xuechun and Feng ${ }^{14)}$, in which increasing MWCNT reduce bulk resistivity of MWCNT/epoxy composites as Besides, the standard deviation of sheet resistance significantly decreases from $9.46 \mathrm{k} \Omega$ to $0.35 \mathrm{k} \Omega$ with an increase of filler loading in ECA from 5 wt.\% to 7 wt.\% respectively, an indication of more reliable measurement of sheet resistance obtained ${ }^{15,16)}$.

The rate of decrease of ECA sheet resistance before and after 6 wt.\% MWCNT filler loading shows a significant difference which is $22.07 \mathrm{k} \Omega / \mathrm{wt} . \%$ and $12.73 \mathrm{k} \Omega / \mathrm{wt} . \%$ respectively. Such observation is due to the rate of decrease of ECA resistivity with an increase in filler loading is reduced as filler concentration is beyond the critical filler of concentration, $V_{c}$, in $\mathrm{ECA}^{5,17)}$. On the other hand, the cured pressure of epoxy is high as the MWCNT filler loading reaches the volume of the percolation threshold, resulted in a significant number of percolated linkages are formed. Hence, the ECA resistivity slightly changes with a further increase of MWCNT filler loading8,17,18).

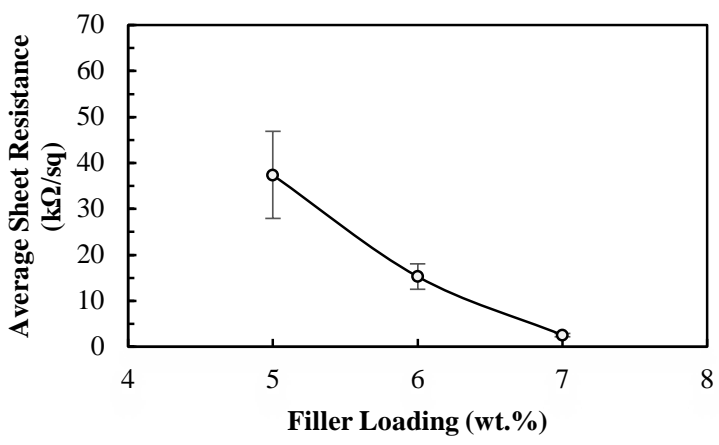

Fig. 3: The plot of ECA average sheet resistance with varying MWCNT filler loading

\subsection{Surface Microstructure and Roughness}

A summary of the experimental results following surface roughness using a stylus profilometer on asreceived and surface-treated aluminum substrates are given in Table 1 , in which an average value is attained from a minimum of 5 sample measurements for each surface condition. The chemically etched substrate exhibits the highest surface roughness up to $2.60 \pm 0.30 \mu \mathrm{m}$, which attributed to deep valleys and high peaks distribute throughout the substrate surface observed in the 3D profile image. The as-received aluminum substrate has the lowest surface roughness due to no surface treatment applied and with the oxide layer present on the substrate surface, provide uniform shallow valleys and low peaks on the entire surface.

Based on the 2-D microscopic image in Fig. 4 (a) \& (b) at 200x magnification, an as-received aluminum substrate surface exhibits the formation of aluminum oxide crack 
with small voids while chemically etched aluminum substrate has high dense of voids with large opening structure. The chemically etched substrate has deeper voids on its entire surface as compared to the as-received substrate, as depicted in Fig. 4 (c) \& (d).

Table 1. Average of surface roughness of the as-received and chemically etched aluminum substrate

\begin{tabular}{|c|c|}
\hline Surface Treatment & Average Surface Roughness, $\boldsymbol{R}_{\boldsymbol{a}}(\boldsymbol{\mu m})$ \\
\hline As-Received & $0.36 \pm 0.02$ \\
\hline Chemical Etching & $2.60 \pm 0.30$ \\
\hline
\end{tabular}

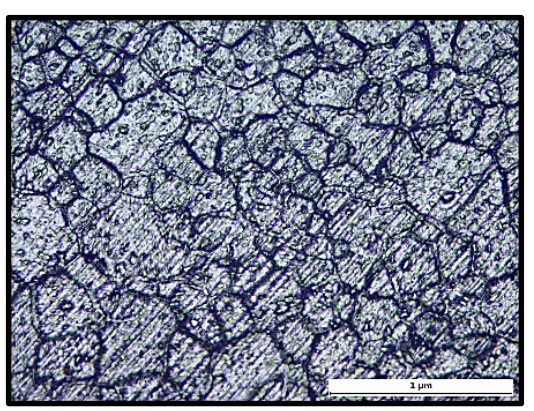

(a)

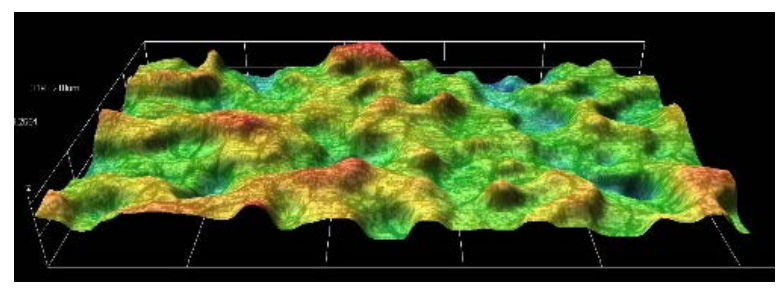

(b)

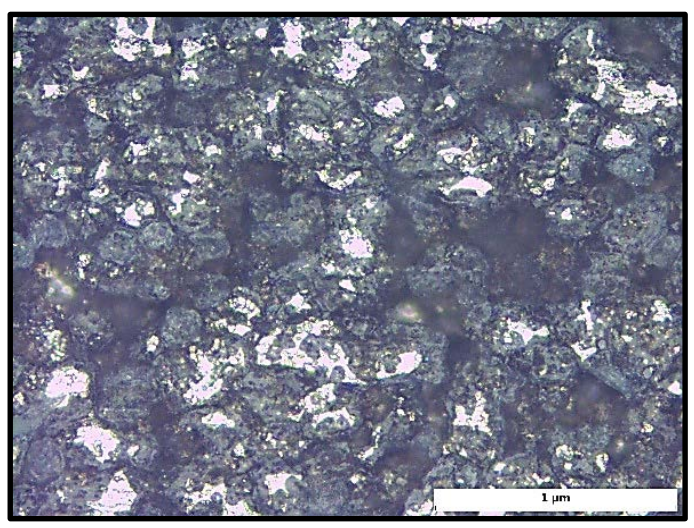

(c)

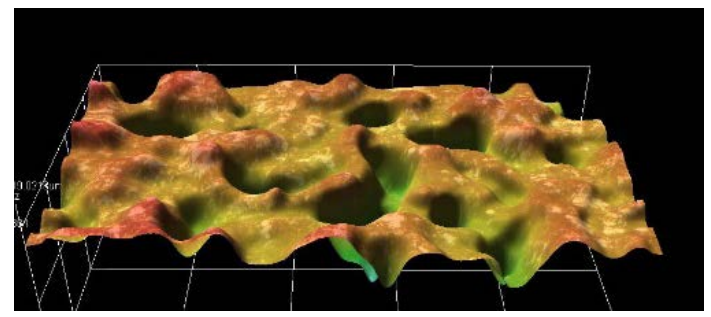

(d)

Fig. 4: 2-D and 3-D microscopic images of (a) \& (c) asreceived and (b) \& (d) chemically etched aluminium substrate respectively

\subsection{Contact Angle}

Based on the theory on wettability ${ }^{19)}$, the low contact angle experienced by a liquid in a specified surface indicates that the liquid has good wettability toward the surface. The wettability will have an impact on surface adhesion performance between ECA and substrate, due to excellent wettability is influenced by the excellent ability of ECA to cover all bumps and voids, which results in great adhesion properties of the bond.

From the results from contact angle measurement in Table 2, the chemically etched substrate has the lowest contact angle, an indication of excellent surface wettability since higher surface roughness promotes the better spreading of liquid to the substrate surface ${ }^{9}$. Furthermore, the open structure of voids or crevices on the surface contributes to a high tendency of the water to fill in and reduce contact angle ${ }^{20)}$. The as-received substrate has a smooth surface indicating the low surface area to be covered by water. Therefore, the substrate has a significantly higher contact angle than a chemically etched substrate.

Table 2. Water droplet behavior and average contact angle of as-received and chemically-etched aluminum substrate

\begin{tabular}{|c|c|c|}
\hline $\begin{array}{c}\text { Surface } \\
\text { Treatment }\end{array}$ & Water Droplet Behaviour & $\begin{array}{c}\text { Average Contact } \\
\text { Angle }\left({ }^{\circ}\right)(\theta)\end{array}$ \\
\hline $\begin{array}{c}\text { As- } \\
\text { Received }\end{array}$ & & $74.47 \pm 5.29$ \\
\hline $\begin{array}{c}\text { Chemical } \\
\text { Etching }\end{array}$ & & $16.78 \pm 4.40$ \\
\hline
\end{tabular}

\subsection{Lap Shear Test}

The ECA with 0 wt.\% (only applied on as-received), 5 wt.\%, 6 wt.\%, and 7 wt.\% MWCNT filler loadings were subjected to lap shear test and the results obtained are shown in Fig. 5. Based on the result, the shear strength of ECA bonded to the as-received aluminium substrates is greatly increase with increasing MWCNT filler loading, from 0 wt.\% to 5 wt.\%. More specifically, the shear strength of the ECA bonded to as-received and chemically etched substrate increase slightly from 5 wt.\% to 6 wt.\%. Such observation is possibly due to the addition of MWCNT filler into the epoxy, with reinforced the composites thus contribute to an increase in the ECA toughness and resist the formation of crack growth in the composites $^{21)}$. Moreover, the presence of MWCNT in ECA induces the formation of a new surface which increases the energy absorbed ${ }^{22)}$ and the mechanical load 
can be efficiently transferred from epoxy to the high stiffness MWCNT.

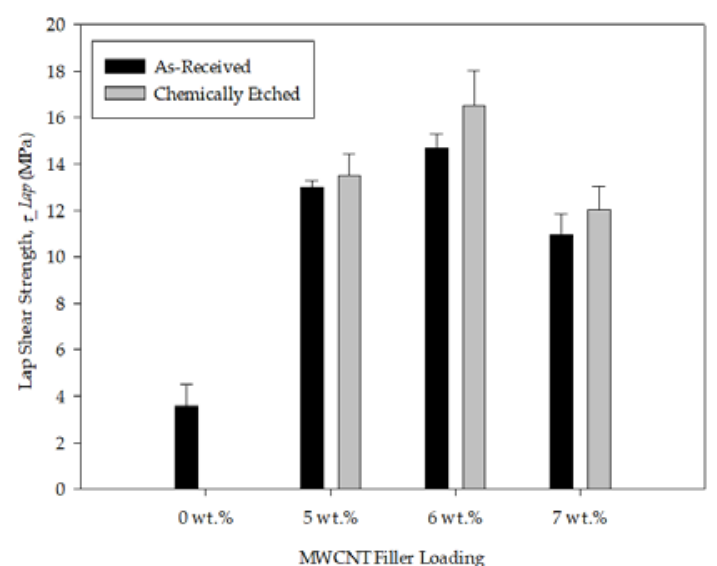

Fig 5: Shear strength of varying filler loading of ECA bonded to as-received and chemically etched aluminium substrates

However, further increase of the MWCNT filler loading from 6 wt.\% to 7 wt.\% has resulted in a decrease of the ECA shear strength bonded to both substrates surface condition. At this point, the MWCNT filler, which has high surface energy, tends to aggregate resulting in poor dispersion and consequently reduce the ECA mechanical strength ${ }^{23-25)}$. It is possibly due an increase in the ECA viscosity with increasing MWCNT filler loading before the curing process, which reduces the mobility of MWCNT in the epoxy and affects the dispersion of MWCNT in the ECA. Thus, the partially aggregated MWCNT bundles could possibly act as stress concentrators that reduce the interfacial adhesion between MWCNT/epoxy, which resulted to slippage of filler when load is subjected to the ECA ${ }^{22,25,26)}$.

Moreover, the high viscosity of ECA reduce the adhesion strength of ECA towards the aluminum substrate since high viscosity fluid exhibit low wettability ${ }^{19)}$. Hence, it reduces both the tendency of ECA to penetrate the voids and the effective bond area between the ECA and the substrate interface ${ }^{27,28)}$. Furthermore, the high viscosity of ECA due to high filler loading creates the bubbles and reduces the ability of bubbles removal, which reduces the mechanical bonding properties between the ECA/substrate interface ${ }^{25)}$.

Based on Fig.6, the ECA with 5 wt.\% and 6 wt.\% MWCNT loading failed in adhesive-cohesive mode while ECA with 7 wt.\% MWCNT loading exhibit adhesive failure mode. Overall, adhesive-cohesive failure mode of ECA exhibit higher shear strength as compared to adhesive failure mode, suggesting high adhesion strength between ECA/substrate interface as a result of large surface area of contact between epoxy/substrate interface, which yield in strong mechanical contact ${ }^{29)}$. Such observation is in agreement with the literature which studied the effect of surface treatment on adhesively bonded aluminium-aluminium joints which argued that the adhesive-cohesive failure showed higher failure loads as compared to those of adhesive type of failure ${ }^{30)}$.

\begin{tabular}{|l|l|l|l|}
\hline $\begin{array}{l}\text { Surface } \\
\text { Treatment }\end{array}$ & ECA Failure Behaviour & $\begin{array}{l}\text { Mode of } \\
\text { Failure }\end{array}$ \\
\hline $\begin{array}{l}|c| \\
\text { As- } \\
\text { Received }\end{array}$ & & & Adhesive- \\
Cohesive
\end{tabular}

Fig. 6: Visual observation of the ECA bonded to chemically etched aluminum substrates with filler loading of 5,6 and 7 wt.\% showing the respective adhesive failure mode.

Moreover, adhesive failure at high MWCNT filler loading suggest low mechanical interlocking strength between epoxy/substrate interface which can be attributed 
to the presence of large amount of MWCNT particles between epoxy/substrate interface, thus, induced to low surface area of contact between the epoxy/substrate interface. Hence, the ECA bonded to an adhesive failure have relatively inferior shear strength than ECA bonded to adhesive-cohesive failure.

In addition, Fig. 7 give the SEM micrographs of ECA bonded to chemically etched aluminum substrates with filler loading of (a) 6 wt.\% and (b) 7 wt.\% fractured surface of at $200 \mathrm{x}$ magnification respectively. It is apparent that the fracture surface of ECA with 7 wt.\% MWCNT filler loading exhibit denser volume of voids with the rougher surface than ECA with 6 wt.\%. MWCNT filler loading. High content of voids or hollow structures in ECA with 7 wt.\% MWCNT filler loading reduces the contact area between the ECA and the substrate. Hence, insufficient anchoring of epoxy towards the substrate occurs $^{23)}$.

Also, an increase in the conductive filler loading in ECA means that the volume fraction of epoxy is reduce, relative to the total volume of ECA reduces, therefore, cause a decrease in the composites shear strength since epoxy is not present in continuous form and unable to provide a good polymer network ${ }^{23,31)}$. Besides, at high MWCNT filler loading, there is less surface contact area between epoxy/substrate interface to provide adhesion properties ${ }^{16)}$ since numerous of MWCNT exist between the epoxy/substrate interface, in which the MWCNT does not have a strong bond to the substrate.

Based on the results following lap shear test for the ECA bonded to as-received and chemically etched substrates, there is a clear trend on the resultant shear strength of the ECA with increasing MWCNT filler loading, which is similar to the trend observed in an earlier studies using CNT/polymer composites as reported by Loos and Manas-Zloczower ${ }^{32)}$ and experimental result on mechanical properties of ICA demonstrated by Wu et al. 17).

The chemically etched substrate provides the highest surface roughness, which introduces to the large interfacial area between aluminum and ECA which enhances the mechanical interlocking of the interface ${ }^{33)}$. The high surface roughness of the chemical etched substrate is due to the formation of a high density of deep voids and high peaks of surface protrusion on its entire surface while the as-received substrate has a smoother surface with less surface protrusion which contributes to low surface roughness. The combination of high surface roughness and good wettability of adhesive toward aluminum surface yields an excellent bond strength ${ }^{9)}$ as the enhancement of the effective bond area. Other factors that may contribute to good adhesion are the chemical etching process activated and cleaned aluminum surface and dissolved natural alumina layer or weakly bound oxide layer which the natural alumina can reduce the ability of the adhesive to spread ${ }^{9}$.

Based on these experimental results, clearly the chemically etched substrate promotes the higher bond strength than the as-received substrate (surface solely wiped with acetone, which is in good agreement with published literature on the effect of surface treatment on the shear strength of aluminum adhesive single-lap-joint in the past literature ${ }^{30}$.In their study, it was argued that the chemically treated of both aluminum substrate provides a higher ECA load of failure as compared to only one substrate is chemically treated ${ }^{30}$.

Moreover, the findings from this study is similar to the work reported on the relation between aluminum surface roughness and adhesive bond shear strength. In their study, it was argued that the highest adhesive shear strength is achieved with an aluminum surface roughness at $2.05 \pm 0.19 \mu \mathrm{m}$, which is in close proximity to the chemically etched substrate surface roughness in this research project that yields the highest ECA shear strength $^{34)}$.

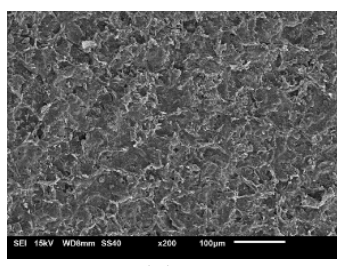

(a)

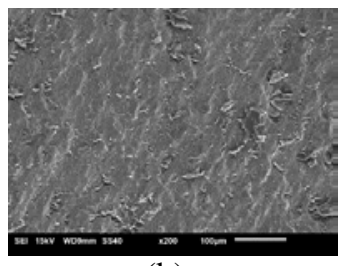

(b)
Fig. 7: SEM micrograph images of fracture surface of ECA bonded to chemically etched aluminum substrates with filler loading of (a) 6 wt.\% and (b) 7 wt.\% at 200x magnification respectively

\section{Conclusions}

Based on the experimental results attained from this study, the following conclusions can be drawn:

i. There is a linear decrease in the volume resistivity with the MWCNT filler loading, suggesting that higher filler loading can significantly improve the electrical conductivity of an ECA. Here, as the filler loading is increased, the electrical pathways are formed due to contacts between the particles where the volume resistivity continues to decrease.

ii. Chemically-etched aluminum substrate yield in the highest surface roughness and highest surface wettability of the sample. Furthermore, large opening voids and deep valleys are observed on the substrate surface.

iii. A combination of excellent surface wettability and high surface roughness of the substrate yield in the excellent mechanical properties of the ECA.

iv. Nonetheless, from SEM micrographs, with relatively higher MWCNT filler loading, traces of voids and hollow structures in the ECA are present, which yield in poorer mechanical properties.

\section{Acknowledgments}

This work is fully supported by the FRGS/2018/FKMCARE/F00372 grant from the Ministry of Education Malaysia. Besides, the authors also acknowledge the 
Faculty of Mechanical Engineering, Universiti Teknikal Malaysia Melaka (UTeM), for the technical support in completing the research work.

\section{References}

1) S. Fadzullah, and Z. Mustafa, "Green Approaches to Biocomposite Materials Science and Engineering," in: P.C. Verma, Deepak, Jain, Siddharth, Zhang, Xiaolei, Gope (Ed.), Green Approaches to Biocomposite Mater. Sci. Eng., IGI Global, 2016: pp. 125-147. doi:10.4018/978-1-5225-0424-5.

2) M. Maurya, N.K. Maurya, and V. Bajpai, "Effect of sic reinforced particle parameters in the development of aluminium based metal matrix composite," Evergreen, 6 (3) 200-206 (2019).

3) M.M. Nasaruddin, S.H. Sheikh Md Fadzullah, G. Omar, Z. Mustafa, M. Ramli, M.Z. Akop, I.S. Mohamad, and B. çoşut, "The effect of aspect ratio on multi-walled carbon nanotubes filled epoxy composite as electrically conductive adhesive," $J$. Adv. Manuf. Technol., 13 (1) 133-144 (2019).

4) M.M. Nasaruddin, S.H. Sheikh Md.Fadzullah, and G. Omar, "Preliminary investigation on multi-walled carbon nanotubes filled epoxy composite as electrically conductive adhesive," Int. J. Recent Technol. Eng., 8 (IS5) 28-32 (2019).

5) and C.P.W. Li, Yi Grace, Daniel Lu, ed., "Electrical conductive adhesives with nanotechnologies," Springer Science \& Business Media, 2009.

6) J.. Sow, S.H. Sheikh Md Fadzullah, M.M. Nasaruddin, N.A.. Masripan, M.R. Mansor, and M.. Salim, "Functional properties of hybrid MWCNT-Ag filled epoxy electrically conductive adhesive,” in: Proc. Mech. Eng. Res. Day 2019, 2019: pp. 84-85. http://www.ghbook.ir/index.php?name=فر و هاى م رسانه نوين وشانه $\mathrm{d}=13650$ \&page $=73 \&$ chkhashk=ED9C9491B4\&Item id=218\&lang=fa\&tmpl=component.

7) P.P.D.K. Wulan, J.A. Ningtyas, and M. Hasanah, "The effect of nickel coating on stainless steel 316 on growth of carbon nanotube from polypropylene waste," Evergreen, 6 (1) 98-102 (2019). doi:10.5109/2328411.

8) Y. Kwon, B.S. Yim, J.M. Kim, and J. Kim, "Dispersion, hybrid interconnection and heat dissipation properties of functionalized carbon nanotubes in epoxy composites for electrically conductive adhesives (ecas)," Microelectron. Reliab., $51 \quad$ (4) 812-818 (2011). doi:10.1016/j.microrel.2010.11.005.

9) K. Leena, K.K. Athira, S. Bhuvaneswari, S. Suraj, and V.L. Rao, "Effect of surface pre-treatment on surface characteristics and adhesive bond strength of aluminium alloy,” Int. J. Adhes. Adhes., 70 265-270 (2016). doi:10.1016/j.ijadhadh.2016.07.012.
10) S. Correia, V. Anes, and L. Reis, "Effect of surface treatment on adhesively bonded aluminiumaluminium joints regarding aeronautical structures," Eng. Fail. Anal., 84 (June 2017) 34-45 (2018). doi:10.1016/j.engfailanal.2017.10.010.

11) M.M. Reddy, S. Vivekanandhan, M. Misra, S.K. Bhatia, and A.K. Mohanty, "Biobased plastics and bionanocomposites: current status and future opportunities,” Prog. Polym. Sci., 38 (10-11) 16531689 doi:10.1016/j.progpolymsci.2013.05.006.

(2013).

12) N.M. Zain, S.H. Ahmad, and E.S. Ali, "Effect of surface treatments on the durability of green polyurethane adhesive bonded aluminium alloy,” Int. J. Adhes. Adhes., 55 43-55 (2014). doi:10.1016/j.ijadhadh.2014.07.007.

13) Zhang, R., Agar, J.C. and Wong, C.P., "Conductive polymer composites,” Encycl. Polym. Sci. Technol., (2002).

14) L. Xuechun, and L. Feng, "The improvement on the properties of silver-containing conductive adhesives by the addition of carbon nanotube," Proc. Sixth IEEE CPMT Conf. High Density Microsyst. Des. Packag. Compon. Fail. Anal. (HDP '04), 382-384 (2004). doi:10.1109/HPD.2004.1346734.

15) K. Mantena, "ELECTRICAL AND MECHANICAL PROPERTIES OF MWCNT FILLED CONDUCTIVE ADHESIVES ON LEAD FREE SURFACE FINISHED PCB's," University of Kentucky, 2009. https://www.scopus.com/inward/record.uri?eid=2s2.084876939808\&partnerID=40\&md5=bcfc80d3c1ca6 41a3d40f1b347d277c0.

16) J. Li, and J.K. Lumpp, "Electrical and mechanical characterization of carbon nanotube filled conductive adhesive,” Aerosp. Conf. IEEE, (2006).

17) H.P. Wu, X.J. Wu, M.Y. Ge, G.Q. Zhang, Y.W. Wang, and J. Jiang, "Properties investigation on isotropical conductive adhesives filled with silver coated carbon nanotubes,” Compos. Sci. Technol., 67 (6) 1182-1186 (2007). doi:10.1016/j.compscitech.2006.05.010.

18) S. Yu, M.N. Tong, and G. Critchlow, "Use of carbon nanotubes reinforced epoxy as adhesives to join aluminum plates,” Mater. Des., 31 (SUPPL. 1) S126S129 (2010). doi:10.1016/j.matdes.2009.11.045.

19) Matthews, F.L. and Rawlings, R.D., "Composite materials: engineering and science,” CRC press, 1999.

20) C.W. Jennings, "Surface roughness and bond strength of adhesives,” J. Adhes., 4 (1) 25-38 (1972). doi:10.1080/00218467208072208.

21) V.K. Srivastava, "Effect of carbon nanotubes on the strength of adhesive lap joints of $\mathrm{c} / \mathrm{c}$ and $\mathrm{c} / \mathrm{csic}$ ceramic fibre composites,” Int. J. Adhes. Adhes., 31 (6) 486-489 (2011). doi:10.1016/j.ijadhadh.2011.03.006.

22) Zohar, E., Baruch, S., Shneider, M., Dodiuk, H., 
Kenig, S., Tenne, R. and Wagner, H.D., "The effect of ws2 nanotubes on the properties of epoxy-based nanocomposites,” J. Adhes. Sci. Technol., 25 (13) 1603-1617 (2011).

23) J. Trinidad, L. Chen, A. Lian, and B. Zhao, “Solvent presence and its impact on the lap-shear strength of sds-decorated graphene hybrid electrically conductive adhesives," Int. J. Adhes. Adhes., 78 (June) 102-110 (2017). doi:10.1016/j.ijadhadh.2017.06.012.

24) Zandiatashbar, A., Picu, R.C. and Koratkar, N., "Mechanical behavior of epoxy-graphene platelets nanocomposites,” J. Eng. Mater. Technol., 134 (3) (2012).

25) J. Shen, W. Huang, L. Wu, Y. Hu, and M. Ye, "The reinforcement role of different amino-functionalized multi-walled carbon nanotubes in epoxy nanocomposites,” Compos. Sci. Technol., 67 (15-16) 3041-3050 doi:10.1016/J.COMPSCITECH.2007.04.025.

26) B.S. Yim, and J.M. Kim, "Electrical and mechanical properties of multiwalled carbon nanotubesreinforced solderable polymer nanocomposites," $J$. Mater. Sci. Mater. Electron., 26 (3) 1678-1689 (2015). doi:10.1007/s10854-014-2592-9.

27) S.G. Prolongo, and A. Ureña, "Effect of surface pretreatment on the adhesive strength of epoxyaluminium joints,” Int. J. Adhes. Adhes., 29 (1) 23-31 (2009). doi:10.1016/J.IJADHADH.2008.01.001.

28) S.J. Hitchcock, N.T. Carroll, and M.G. Nicholas, "Some effects of substrate roughness on wettability," J. Mater. Sci., $16 \quad$ (3) 714-732 (1981). doi:10.1007/BF02402789.

29) N.M. Zain, S.H. Ahmad, and E.S. Ali, "Effect of surface treatments on the durability of green polyurethane adhesive bonded aluminium alloy," Int. J. Adhes. Adhes., 55 43-55 (2014). doi:10.1016/j.ijadhadh.2014.07.007.

30) S. Correia, V. Anes, and L. Reis, "Effect of surface treatment on adhesively bonded aluminiumaluminium joints regarding aeronautical structures,” Eng. Fail. Anal., 84 (November 2017) 34-45 (2018). doi:10.1016/j.engfailanal.2017.10.010.

31) W. Qiao, H. Bao, X. Li, S. Jin, and Z. Gu, "Research on electrical conductive adhesives fi lled with mixed fi ller,” $48 \quad 159-163 \quad$ (2014). doi:10.1016/j.ijadhadh.2013.07.001.

32) M.R. Loos, and I. Manas-Zloczower, "Reinforcement efficiency of carbon nanotubes - myth and reality," Macromol. Theory Simulations, 21 (2) 130-137 (2012). doi:10.1002/mats.201100099.

33) K. Yasuda, and R. Saito, "Effect of surface roughening of aluminum plates on the strength of bonds formed between aluminum and polyphenylene sulfide by thermosonic bonding effect of surface roughening of aluminum plates on the strength of bonds formed between aluminum and polyphen," 61
(2014). doi:10.1088/1757-899X/61/1/012007.

34) A. Ghumatkar, R. Sekhar, and S. Budhe, "Experimental study on different adherend surface roughness on the adhesive bond strength," Mater. Today Proc., $4 \quad$ (8) 7801-7809 (2017). doi:10.1016/J.MATPR.2017.07.115. 